\title{
NIETZSCHE E A CRÍTICA DA DEMOCRACIA
}

\author{
Scarlett Marton \\ Universidade de São Paulo
}

\begin{abstract}
Nietzsche, this frankly anti-democratic thinker, makes to the democracy, questioning and evaluating the arguments which he elaborates to do so. Focusing the analysis on the idea of equality, it is intended to examine the consequences of the combat the philosopher wages against the so-called "modern ideas" and his position in favor of aristocratism.
\end{abstract}

Keywords: Nietzsche, politics, democracy, criticism, aristocracy.

Resumo: o propósito do presente texto é discutir a crítica que Nietzsche, este pensador francamente anti-democrático, faz à democracia, questionando e avaliando os argumentos que ele elabora para tanto. Centrando a análise na ideia de igualdade, pretende-se examinar as consequências do combate que 0 filósofo trava contra as chamadas "ideias modernas" e de sua tomada de posição em favor do aristocratismo.

Palavras-chave: Nietzsche, política, democracia, crítica, aristocracia.

Durante muito tempo, os comentadores de modo geral negligenciaram os aspectos políticos do pensamento nietzschiano ${ }^{1}$. Dentre os vários fatores que contribuíram para tanto, há que se notar a necessidade que então se impunha de desqualificar os diferentes usos e apropriações políticas das ideias de Nietzsche.

Contudo, há cerca de vinte anos, começaram a surgir trabalhos que se interrogam sobre a existência ou não de uma dimensão política nos textos do filósofo; eles se situam sobretudo no contexto dos estudos publicados em

\footnotetext{
1 Uma das raras exceções, durante o período que vai do final da Segunda Grande Guerra até 1985, é 0 livro de S. Goyard-Fabre, Nietzsche et la question politique, Paris, Sirey, 1977.
} 
língua inglesa ${ }^{2}$. Enquanto certos autores não aceitam que o pensamento nietzschiano possa apresentar uma dimensão política stricto sensu ${ }^{3}$, outros sustentam, ao contrário, que Nietzsche é um pensador político ${ }^{4}$. Abraçando essa última perspectiva, há autores pós-estruturalistas que tentam colocar a concepção nietzschiana de agon a serviço de uma nova compreensão de democracia $^{5}$ e há aqueles que defendem que ela não poderia de modo algum ser tomada nessa direção ${ }^{6}$. Trazendo a marca do tempo e do espaço em que surgem, certos textos se deixam levar a polêmicas localizadas ${ }^{7}$; limitando-se

2 Cf. P. Bergmann, Nietzsche. The "Last Anti-Political German", Bloomington, Indiana University Press, 1987; K. Ansell-Pearson, An Introduction to Nietzsche as Political Thinker, Cambridge, University Press, 1994; D. Owen, Nietzsche, Politics and Modernity. A Critical of Liberal Reason, Londres, Thousand Oaks, 1995; A. McIntyre, The Sovereignty of Joy. Nietzsche's Vision of Grand Politics, Toronto, University of Toronto Press, 1997. Cf. também o estudo em língua alemã de H. Ottmann, Philosophie und Politik bei Nietzsche, Berlin, de Gruyter, 1987.

3 Cf. por exemplo T.H.Brobjer, "The Absence of Political Ideals in Nietzsche's Writings", in: NietzscheStudien 27 (1998), p. 300-318. O autor dedica-se a examinar os textos em que Nietzsche trata das Leis de Manu. No seu entender, essas passagens do Crepúsculo dos ídolos (Os "melhoradores" da humanidade, §3) e do Anticristo ( $\S 56,57$ e 58) constituem os enunciados "políticos" mais problemáticos de Nietzsche; eles não exprimem um ideal político, mas fazem parte da crítica que o filósofo dirige ao cristianismo e à modernidade. Ora, nessa medida, Brobjer acaba por endossar a tese de que a política, a moral e a religião se acham estreitamente ligadas no quadro do pensamento nietzschiano. Cf. numa outra direção P. Sedgwick, "Violence, Economy and Temporality. Plotting the Political Terrain of On the Genealogy of Morality", in: Nietzsche-Studien 34 (2005), p.163-185. A partir da análise de certas passagens da Genealogia da moral, o autor tenta estabelecer uma relação entre as considerações de Nietzsche sobre a economia e sua concepção da "grande política".

${ }^{4}$ No seu artigo "Virtuosos of Contempt': An Investigation of Nietzsche's Political Philosophy Through Certain Platonic Political Ideas" (in: Nietzsche-Studien 21 (1992), p. 184-210), a partir de uma comparação entre a filosofia nietzschiana e o pensamento platônico, Mclntyre defende a ideia de que Nietzsche é um pensador político. Em primeiro lugar, porque o autor de Zaratustra teria em vista uma transformação cultural fundamental, que exigiria a criação de uma hierarquia espiritual e uma nova tábua de valores; depois, porque não se poderia confundir a "grande política" com o poder político do Estado. Ora, concebida dessa maneira, a política não constituiria, no meu entender, uma dimensão particular do pensamento nietzschiano; ela vem integrar a investigação sobre os valores.

${ }^{5}$ Cf. M. Warren, Nietzsche and Political Thought, Cambridge, Mass., 1988; W. Connoly, Political Theory and Modernity, Oxford, University Press, 1989; B. Honig, Political Theory and the Displacement of Politics, Ithaca, Cornell University Press, 1993; L. J. Hatab, A Nietzschean Defense of Democracy. An Experiment in Postmodern Politics, Chicago, Open Court, 1995; A. D. Schrift, "Nietzsche for Democracy?", in: Nietzsche-Studien 29 (2000), p. 220-232.

${ }^{6}$ Cf. D. W. Conway, Nietzsche and the Political, Londres, Routledge, 1997; F. Appel, Nietzsche contra Democracy, Ithaca, Cornell University Press, 1999; C. D. Acampora, "Demos Agonists Redux. Reflections of the Streit of Political Antagonism", in: Nietzsche-Studien 32 (2003), p. 374-390.

${ }^{7}$ Cf. por exemplo D. Dombowsky, "A Response to Thomas H. Brobjer's 'The Absence of Political Ideals in Nietzsche's Writings", in: Nietzsche-Studien 30 (2001), p. 387-393 e Th. H. Brobjer, "Nietzsche as Political Thinker. A Response to D. Dombowsky", in: Nietzsche-Studien 30 (2001), p. 394-396; D. Dombowsky, "A Response to Alan D. Schrift's 'Nietzsche for Democracy?'”, in: Nietzsche-Studien 31 
a adotar um ponto de vista específico, eles respondem com frequência a interesses pontuais ${ }^{8}$.

A partir do exame do corpus nietzschiano em seu conjunto, não hesito em afirmar que as reflexões de Nietzsche sobre as questões relativas ao poder não chegam a constituir uma teoria política acabada. Nietzsche não se apresenta como um teórico do poder no sentido estrito do termo; tampouco se quer um analista político. Nem por isso ele deixa de refletir sobre temas centrais da filosofia política assim como problemas candentes de sua época. São freqüentes as vezes em que se detém no exame das relações entre o indivíduo e o Estado e também aquelas em que se empenha em analisar o Segundo Reich e Bismarck, o sufrágio universal e os exércitos nacionais, os partidos políticos e a situação da imprensa, o desaparecimento das nações e a unificação da Europa. Embora atento a essa ordem de questões, não lhes confere estatuto próprio, não as enquadra num domínio particular do conhecimento nem delas trata com metodologia específica. Ao contrário, em sua obra, a política aparece estreitamente vinculada à moral e à religião; melhor ainda: moral, política e religião constituem ponto nodal em seu pensamento. Intimamente ligadas, integram um campo de investigação mais amplo: são objeto da crítica dos valores.

Meu propósito consiste aqui em discutir a crítica que este pensador francamente anti-democrático faz à democracia, questionando e avaliando os argumentos que ele elabora para tanto. Centranto a análise na ideia de igualdade, pretendo examinar as consequências do combate que Nietzsche trava contra as chamadas "ideias modernas" e de sua tomada de posição em favor do aristocratismo.

Em seus escritos, Nietzsche adverte repetidas vezes que "é preciso armar os fortes contra os fracos" ${ }^{\prime 9}$. Além do número, os fracos teriam a seu

(2002), p. 278-290 et A. D. Schrift, "Response to Don Dombowsky", in: Nietzsche-Studien 31 (2002), p. 291-297.

${ }^{8} \mathrm{~A}$ propósito dos estudos recentemente publicados sobre Nietzsche enquanto pensador politico, ver $\mathrm{H}$. Siemens, "Nietzsche's Political Philosophy: A Review of Recent Literature", in: Nietzsche-Studien 30 (2001), p. 508-526.

${ }^{9}$ Cf. KSA 13.304, fragmento póstumo 14 [123] da primavera de 1888, onde declara: "por mais curioso que isso pareça: é preciso sempre armar os fortes contra os fracos, os felizes contra os infelizes, os sadios contra os depravados e os que têm tara hereditária". Utilizo as edições das obras de Nietzsche (Werke. Kritische Studienausgabe (KSA). Berlim: Walter de Gruyter \& Co., 1967/1978) e de sua correspondência (Sämtliche Briefe. Kritische Studienausgabe (KSB). Berlim: Walter de Gruyter \& Co., 
favor a maestria na arte de trapacear. Atribuindo importância maior ao instinto de conservação do que à vida, desde logo, desenvolveram os talentos da dissimulação; para evitar o confronto que não poderiam suportar, muito cedo aprenderam a agir de maneira insidiosa. Com isso, esperavam conservar a qualquer preço a própria existência. No entender do filósofo, dessa estratégia faz parte o aparecimento das "ideias modernas". Tanto é que ele escreve num fragmento póstumo: "cristianismo, revolução, abolição da escravatura, direitos iguais, filantropia, amor à paz, justiça, verdade: todas essas grandes palavras só têm valor na luta enquanto estandarte: não como realidade, mas como termos pomposos para algo completamente diferente (e até oposto!)" ${ }^{\text {"10 }}$. É desse ponto de vista que o filósofo considera acontecimentos históricos, correntes de ideias, sistemas de governo; é também nesses termos que encara a democracia, o socialismo, o anarquismo; é dentro desses parâmetros que os avalia.

Analisar as "ideias modernas" é um dos propósitos que Nietzsche se coloca em grande parte de seus escritos. Ao apresentar uma visão retrospectiva de sua obra no Ecce homo, ele afirma, por exemplo, que Para além de bem e mal "é, em todo o essencial, uma crítica da modernidade, não excluídas as ciências modernas, as artes modernas, mesmo a política moderna" ${ }^{\text {"11 }}$. Esclarecendo o propósito que persegue com esse seu livro, elucida ao mesmo tempo a amplitude do objeto de sua crítica. Pelo seu crivo, o filósofo fará passar o sentido histórico e a objetividade científica, a música wagneriana e a literatura francesa em geral $^{12}$, a emancipação feminina e a igualdade de direitos. Mas ao deixar claro o objeto que elege para análise, ele também traz à luz a perspectiva que pretende adotar para examiná-lo. Tanto é que, ainda referindo-se a Para além de bem e mal, logo adiante assevera: "O olho, por enorme coerção mal-acostumado a ver longe (...), é forçado aqui a captar com agudeza o que está mais perto, a época, o em torno",

1975/1984) organizadas por Colli e Montinari. Salvo indicação em contrário, é de minha responsabilidade a tradução dos textos de Nietzsche aqui citados.

10 KSA 13.62, fragmento póstumo (371) 11 [135] de novembro de 1887/ março de 1888.

11 KSA 6.350, Ecce Homo, Para além de bem e mal, §2.

12 Vale lembrar que Stendhal figura nesse contexto como uma das raras exceções.

${ }^{13}$ KSA 6.351, Ecce Homo, Para além de bem e mal, §2. 
Nesse seu livro, que se apresenta como "Prelúdio a uma filosofia do futuro", Nietzsche persegue, pois, o propósito de criticar a modernidade, toma por objeto de análise as chamadas "ideias modernas" e, para examinálas, adota a perspectiva do que se dá em primeiro plano. Se estava habituado a "ver longe", agora pretende captar "o em torno". Isso não o impede, porém, de revelar o que por trás dos valores instituídos se esconde e trazer à luz o que eles mesmos escondem. Ao contrário, é precisamente por estar em condições de "transtrocar perspectivas" ${ }^{\prime 14}$ que pode dedicar-se a avaliar as avaliações.

Nesse seu livro, que se intitula Para além de bem e mal, Nietzsche se volta com frequência contra o "espírito de rebanho". Julga que o homem medíocre procura instituir maneiras de agir e pensar universalmente válidas, censurar toda originalidade, reprovar qualquer mudança. Promotor da vida em coletividade, se tentasse viver de outro modo, sucumbiria. "Animal gregário", ele exige ininterruptamente a vitória de cada um sobre si mesmo. Acreditando vê-lo reinar na Europa de seu tempo, o filósofo afirma: "a 'igualdade dos direitos' poderia muito bem converter-se em igualdade de não-direitos" - e prossegue: "quero dizer em guerra geral a tudo o que é raro, insólito, privilegiado, ao homem superior, à alma superior, ao dever superior, à responsabilidade superior, ao sentimento de potência e ao domínio criadores" $"$.

Em várias frentes, Nietzsche empenha-se em combater a ideia de igualdade. No ensaio Sobre verdade e mentira no sentido extra-moral, ele faz ver que as palavras, quando passam a servir para inúmeras experiências análogas à que lhes deu origem, tornam-se conceitos. Produzidos por "igualação do não-igual" e convindo a vários fenômenos, os conceitos mostram-se inapropriados e insuficientes a cada um deles em particular ${ }^{16}$.

\footnotetext{
${ }_{14}$ Nietzsche emprega a expressão Perspektiven umzustellen em KSA 6.266, Ecce Homo, Por que sou tão sábio, §1: "A partir da ótica do doente, olhar para os conceitos e valores mais sadios e, inversamente, da plenitude e certeza da vida rica, olhar para baixo e ver o secreto trabalho do instinto de décadence - esse foi meu mais longo exercício, minha experiência propriamente dita, e, se é que em algo, foi nisso que me tornei mestre. Está agora em minha mão - tenho mão para isso - transtrocar perspectivas". Nesta passagem, recorri à tradução de Rubens Rodrigues Torres Filho (a partir de agora RRTF) para o volume Nietzsche - Obras Incompletas da coleção "Os Pensadores", São Paulo, Abril Cultural, 2a edição, 1978.

15 KSA 5.147, Para além de bem e mal, §212 (RRTF).

${ }^{16} \mathrm{Cf}$. KSA 1.879s, Sobre Verdade e Mentira no sentido extra-moral, § 1, onde se lê: "Toda palavra tornase logo conceito justamente quanto não deve servir, como recordação, para a vivência primitiva,
} 
Na Gaia Ciência, procura mostrar que nos fundamentos mesmos em que se baseia a lógica está presente a tendência ilógica a tratar o semelhante como igual $^{17}$. Em Para além de bem e mal, insiste em afirmar que os mecanicistas, ao defenderem a existência de leis na natureza, nada mais fazem do que se curvarem ao impulso democrático dos tempos modernos. $\mathrm{E}$ conclui: "'Por toda parte igualdade diante da lei - nisso a natureza não está de outro modo nem melhor do que nós': um maneiroso pensamento oculto, em que mais uma vez está disfarçada a plebéia hostilidade contra tudo o que é privilegiado e senhor de si"18. Portanto, ao investigar o processo de formação de conceitos, ao examinar a base dos procedimentos lógicos, ao analisar a atitude dos homens de ciência, ele encontra ocasiões propícias para atacar a ideia de igualdade.

Mas, anunciada por religiões ou defendida por correntes políticas, a ideia de igualdade se converte, no entender de Nietzsche, numa ideia falaciosa e astuta. Desde os primeiros tempos, a noção de equilíbrio de forças regulou as relações humanas. Para conservar a própria existência, os indivíduos mais fracos procuraram associar-se. Vivendo gregariamente, esperavam enfrentar os que, mais fortes do que eles, pudessem vir a ameaçá-los. Por outro lado, os adversários - fossem indivíduos ou grupos -, sempre que tivessem forças equivalentes, concluíam a paz e estabeleciam contratos entre si. Assim surgiu a noção de direito. Reconhecendo-me direitos e permitindo-me preservá-los, cada integrante do grupo comportase com prudência, porque me toma como aliado contra uma terceira força que nos ameace; com receio, uma vez que teme confrontar-se comigo; com astúcia, já que espera, em troca, que eu reconheça os seus direitos e lhe permita preservá-los.

Direitos mantêm relações de força; constituem "graus de poder". "A desigualdade de direitos", declara Nietzsche, "é a condição necessária para que os direitos existam. Um direito é sempre um privilégio" $"$. Meus direitos

completamente individualizada e única, à qual deve seu surgimento, mas ao mesmo tempo tem de convir a um sem-número de casos, mais ou menos semelhantes, isto é, tomados rigorosamente, nunca iguais, portanto, a casos claramente desiguais" (RRTF).

17 Cf. KSA 3.471s, A gaia Ciência, §111, onde se lê: "A tendência preponderante, porém, a tratar 0 semelhante como igual, uma tendência ilógica - pois não há em si nada igual -, foi a primeira a criar todos os fundamentos em que assenta a lógica" (RRTF).

${ }^{18} \mathrm{KSA} 5.37$, Para além de bem e mal, §22 (RRTF).

19 KSA 6.243, O Anticristo, §57. 
são essa parte do meu poder que os outros reconhecem e me permitem conservar; meus deveres, os direitos que outros têm sobre mim. Segue-se daí que os direitos duram tanto quanto as relações de forças que lhes deram origem. A partir do momento em que a força de um certo número de indivíduos se reduz consideravelmente, os outros membros do grupo não mais reconhecem os seus direitos. Mas se, ao contrário, sua força aumenta, são eles que não mais garantem os direitos alheios. À medida que as relações de forças sofrem modificações profundas, certos direitos desaparecem e outros surgem. Dessa perspectiva, a igualdade dos cidadãos perante a lei - eco da igualdade dos homens diante de Deus - não passaria de fórmula forjada por quem precisa somar forças para subsistir.

Ora, é sobretudo a ideia de igualdade associada à tendência democrática da modernidade que Nietzsche combate. Não é, pois, por acaso que se volta contra Rousseau. Pregando a igualdade, o autor do Contrato Social pretende voltar a um estado primitivo, natural e puro. De fato, sua maneira de pensar estaria errada desde a base; Rousseau teria se equivocado quanto à relação de causa e efeito que estabeleceu entre a civilização e a moralidade. Da perspectiva nietzschiana, não cabe à civilização a responsabilidade pela má moralidade; ao contrário, é "nossa boa moralidade" a responsável pelo "caráter lamentável de nossa civilização"20. Associando Rousseau à Revolução francesa, Nietzsche não hesita em tomálo como um dos seus "impossíveis"21. Tanto é que, no Crepúsculo dos ídolos, afirma: "pouco me importa a farsa sangrenta a que deu lugar essa Revolução, sua 'imoralidade': o que odeio é sua moralidade rousseauista as pretensas 'verdades' da Revolução, através das quais ela continua a causar efeitos e convencer a pôr do seu lado tudo o que é superficial e mediocre" 22 .

Por tentar impor o que é uniforme, a moralidade rousseauista, que teria de certo modo suscitado esse acontecimento histórico, consistiria sobretudo numa determinada concepção de igualdade: a que entende por

\footnotetext{
20 KSA 3.146, Aurora, §163. O parágrafo intitula-se precisamente "Contra Rousseau".

${ }^{21}$ KSA 6.111, Crepúsculo dos ídolos, Incursões de um extemporâneo, §1.

22 KSA 6.150, Crepúsculo dos ídolos, Incursões de um extemporâneo, §48. Sobre esse ponto, cf. U. Marti, "Der grosse Pöbel- und Sklavenaufstand". Nietzsches Auseinandersetzung mit Revolution und Demokratie, Stuttgart, Metzler, 1993, em particular os capítulos intitulados "Nietzsches Urteil über die Französische Revolution" e "Rousseau, Kant und die Moralität der Revolution".
} 
igualdade precisamente o nivelamento gregário ${ }^{23}$. Ao defendê-la, Rousseau teria contribuido de maneira decisiva para a Revolução francesa. Mas ele teria igualmente contaminado com suas ideias a filosofia kantiana. Referindo-se ao "chinês de Koenigsberg" no prefácio a Aurora, Nietzsche afirma: "Também ele foi mordido pela tarântula-moral Rousseau, também ele tinha no fundo da alma o pensamento do fanatismo moral, do qual um outro discípulo de Rousseau, ou seja, Robespierre, se sentia e se confessava o executor" ${ }^{\prime 24}$.

A partir do exame desse texto, pode-se levantar duas questões. Antes de mais nada, ele revela que a Nietzsche não escapam os rastros deixados pelo pensamento de Rousseau na filosofia de Kant. Se ele não se mostra inovador ao apontar esse fato, lugar comum para a maioria dos comentadores, mostra sua originalidade ao julgá-lo. Kant e também Robespierre, na condição de discípulos do pensador genebrino, teriam herdado o seu fanatismo moral. E o fanatismo - presente, aliás, igualmente em Lutero e em todos os espíritos limitados - traduziria a defesa de convicções profundamente enraizadas, impedindo a descoberta de novas ideias. "O condicionamento patológico de sua ótica", afirma Nietzsche, "faz do convicto o fanático - Savonarola, Lutero, Rousseau, Robespierre, SaintSimon -, o tipo oposto ao espírito forte, tornado livre ${ }^{, 25}$. Por outro lado, esse texto faz ver que Nietzsche está atento às preocupações morais, que se espraiam por toda a obra de Rousseau. Aranha que enreda em sua teia, causa febre e provoca delírios, o cidadão de Genebra teria impresso a sua marca no século XVIII. E assim se caracterizaria o período histórico em que viveu: "Feminismo - Rousseau, reino do sentimento, testemunho da soberania dos sentidos (mentira)"26.

\footnotetext{
${ }^{23}$ A esse propósito, Urs Marti sustenta: "Por moralidade, Nietzsche entende em primeiro lugar a doutrina da igualdade, que, a seu ver, seduz os espíritos medíocres e minou a crença na hierarquia" ("Nietzsches Kritik der Französischen Revolution", in: Nietzsche-Studien 19 (1990), p. 312-335, p. 313). Seguindo bem de perto Urs Marti, Ansell-Pearson afirma: "Ele [Nietzsche] associa Rousseau com o que chama de 'moralidade' da Revolução, querendo dizer a doutrina da igualdade" (Nietzsche contra Rousseau. A Study of Nietzsche's Moral and Political Thought, Cambridge, University Press, 1992, p. 32).

${ }^{24} \mathrm{KSA} 3.14$, Aurora, prefácio, §3.

${ }^{25} \mathrm{KSA} 6.237$, O Anticristo, $§ 54$.

26 KSA 12.440, fragmento póstumo (128) 9[178] do outono de 1887. A esse propósito, cf. também KSA 3.29s, Aurora, §17 e KSA 12.412, fragmento póstumo (87) 9[131] do outono de 1887.
} 
No contexto do pensamento nietzschiano, a figura de Rousseau só adquire contornos mais precisos quando contraposta à de Voltaire. Uma passagem de Humano, demasiado humano permite compreender que Voltaire encarna precisamente a antítese de Rousseau. "Não é Voltaire, com sua natureza comedida, levada a regularizar, purificar, reconstruir, mas Rousseau, suas loucuras e suas meia-mentiras, que suscitaram esse espírito otimista da Revolução, contra o qual lanço o apelo: 'Écrasez l'infâme !' „27. De um lado, as Luzes; de outro, a Revolução francesa. De um lado, o aristocratismo; de outro, a plebe ${ }^{28}$. Ao fazer ricochetear a frase de Voltaire contra Rousseau, o autor de Humano, demasiado humano revela suas preferências. O autor desse livro "para espíritos livres", publicado "em memória de Voltaire no centésimo aniversário de sua morte, em 30 de maio de 1778", reafirma suas predileções.

Que Nietzsche tome a defesa do aristocratismo contra o ideal gregário, fica evidente quando se percorre os seus textos ${ }^{29}$. Contudo, a aristocracia de que fala não é somente fruto de elaboração teórica; em diferentes épocas históricas, supõe encontrá-la. O homem nobre a que se refere não se reduz a mero conceito; em contextos muito precisos, acredita deparar-se com ele. Julga que existiu nos séculos XVII e XVIII com a nobreza francesa, no Renascimento com a comunidade aristocrática de

\footnotetext{
27 KSA 2.299, Humano, demasiado humano, §463.

${ }_{28}$ Nessa direção, cf. G. Campioni, Lectures françaises de Nietzsche, trad. Christel Lavigne-Mouilleron, Paris, PUF, 2001, onde se lê: "A essas 'Luzes' caracterizadas pela figura de Voltaire, Nietzsche opõe com firmeza, desde Humano, demasiado humano, a figura de Rousseau que representa a corrupção do espírito das Luzes numa direção 'fanática' e moral: o primeiro é tão aristocrático e serenamente 'livre', campião da tolerância, quanto o segundo é 'plebeu' e podre de sentimentalismo, intolerante, expressão de fraqueza romântica" (p. 47).

${ }^{29}$ É a posição que também defende Bruce Detwiler. Na conclusão de seu livro, ele afirma: "É difícil pensar em outro autor moderno da estatura de Nietzsche, cuja orientação política seja ao mesmo tempo tão aristocrática e tão radical quanto a sua. Dentre os filósofos modernos, Nietzsche permanece virtualmente só ao insistir que o alvo da sociedade deveria ser a promoção e a elevação do tipo superior até mesmo às expensas do que tradicionalmente se pensou ser bom para todos ou para o maior número" (Nietzsche and the Politics of Aristocratic Radicalism, Chicago, University of Chicago Press, 1990, p. 189). Dentre inúmeras passagens, cf. nessa direção KSA 13.65, fragmento póstumo (371) 11 (140) de novembro de 1887/março de 1888. Vale ainda lembrar que, entusiasmado com a Genealogia da Moral, que Nietzsche Ihe enviara, Georg Brandes decidiu difundir o seu pensamento. Além de proferir uma série de conferências sobre a sua filosofia na Universidade de Copenhague em fevereiro de 1888, escreveu uma resenha do livro, a que dá o título de "Radicalismo aristocrático". Ao que consta, ela foi muito apreciada pelo filósofo, quando de sua publicação.
} 
Veneza e sobretudo na Antiga Grécia com a aristocracia guerreira ${ }^{30}$. Lançando mão dos estudos históricos, o filósofo, sem dúvida, toma partido por um tipo determinado de organização social. Mas não é simplesmente para isso que recorre à história e, sim, para enriquecer a sua crítica dos valores.

Além da contribuição decisiva da pesquisa histórica, Nietzsche conta com o concurso da filologia. No prefácio à Genealogia da Moral, sugere que "algo da escolaridade histórica e filológica, inclusive um inato sentido seletivo em vista de questões psicológicas em geral"31 auxiliaram-no a instaurar o procedimento genealógico e a elaborar a crítica dos valores. Ao deter-se no exame do cristianismo, por certo, recorre à filologia; ao empenhar-se na análise da moral dos ressentidos, sem dúvida, lança mão da história. Não caberia aqui, porém, apreciar o uso (ou apropriação) que ele faz de dados filológicos ou elementos históricos, mas apenas de sublinhar o seu propósito de recorrer a eles em suas reflexões sobre a proveniência e as transformações por que passam os valores. Munido desses elementos, aplica-se então a refletir sobre doutrinas morais, eventos políticos e ensinamentos religiosos. De posse desses dados, dedica-se a examinar a tendência democrática da modernidade.

É enquanto psicólogo que Nietzsche encara o ideário moderno; pretende diagnosticar os móveis ocultos dos que o apóiam. É na qualidade de genealogista que o avalia; quer julgar os valores inconfessados dos que o defendem ${ }^{32}$.

Nietzsche entende que, graças a Rousseau e à Revolução francesa, as "ideias modernas" se impuseram em detrimento de toda ordem hierárquica. É o que o leva a nelas denunciar a obra do cristianismo e o procedimento dos ressentidos. Tanto é que ele assegura na Gaia ciência: "foi a Revolução Francesa que colocou o cetro, solenemente e sem reservas, nas mãos do 'homem bom' (do cordeiro, do asno, do ganso e de tudo o que é

30 Cf. respectivamente KSA 5.285s, Genealogia da Moral, Primeira Dissertação, §16; KSA 6.139s, Crepúsculo dos ídolos, Incursões de um extemporâneo, §38; KSA 3.173s, Aurora §199.

${ }^{31}$ KSA 5.249, Genealogia da Moral, Primeira Dissertação, § 3 (RRTF).

32 Não podemos, por certo, acompanhar Simone Goyard-Fabre, quando afirma referindo-se à Revolução francesa: "É essencialmente enquanto metafísico que Nietzsche - tal como Hegel quanto a esse ponto considera e julga o acontecimento revolucionário" (Nietzsche et la question politique, Paris, Sirey, 1977, p. 99). 
irremediavelmente superficial e estridente, maduro para o manicômio das 'ideias modernas'),"33.

Na Europa de sua época, o filósofo julga testemunhar uma crescente uniformização. Na medida em que se abandona a preocupação com a hierarquia, tem-se de abrir mão das diferenciações. É nesse sentido que Nietzsche escreve no Crepúsculo dos ídolos: "A doutrina da igualdade! Mas não existe veneno mais venenoso: é que parece pregada pela própria justiça, quando é o fim da justiça... 'Aos iguais o igual, aos desiguais o desigual' essa seria a verdadeira divisa da justiça - e o que daí decorre: 'Nunca igualar o desigual",34.

Ao encarar a igualdade como sinônimo de nivelamento gregário e uniformização, Nietzsche faz de seus ataques a esta ideia o cerne argumentativo da crítica que dirige à democracia. Mas já é tempo de perguntar: como conceber a ideia mesma de igualdade? E quais as suas implicações? Para tanto, convém investigar o que se entende por justiça.

Todos sabemos que, na modernidade, justiça pode significar seis tipos de afirmações: a cada um o mesmo; a cada um segundo os seus méritos; a cada um segundo as suas obras; a cada um segundo as suas necessidades; a cada um segundo o seu lugar, classe, estamento; a cada um segundo o que é atribuído por lei, sendo que se pode entender a lei formalmente ou como algo que tem desde sempre um conteúdo. Embora essas concepções sejam incompatíveis entre si, elas têm algo em comum; em todas elas está presente um princípio de ação, segundo o qual os seres de uma mesma categoria essencial devem ser tratados do mesmo modo. Contudo, nenhuma dessas definições nem o denominador formal que lhes é comum fazem mais do que fixar limites dentro dos quais se pode discutir o conceito de justiça, conceito esse que requer tanto uma formalização quanto a referência constante a bases históricas.

Importa aqui notar que o princípio de ação, comum a todas essas definições, se baseia numa ideia central: a de igualdade. É certo que se pode falar em igualdade em diferentes registros: igualdade matemática, igualdade geométrica, igualdade lógica, igualdade formal, igualdade material,

\footnotetext{
${ }^{33}$ KSA 3.586, A gaia Ciência §350. A propósito da crítica que Nietzsche faz dessa divisa revolucionária, cf. o meu "Nietzsche e a Revolução Francesa", in Extravagâncias. Ensaios sobre a filosofia de Nietzsche. São Paulo: Barcarolla, $3^{a}$ ed., 2009, p. 183-198.

34 KSA 6.150, Crepúsculo dos ídolos, Incursões de um extemporâneo, §48.
} 
igualdade política, igualdade jurídica. $\mathrm{Na}$ Declaração dos direitos do homem, por exemplo, o artigo primeiro define: "todos os homens nascem e permanecem livres e iguais em direitos". Essa afirmação reveste a forma de uma asserção de fato, que diz respeito à natureza das coisas. Mas ela não designa algo real e sim um ideal que não se realiza em sociedade alguma; ela aponta, pois, apenas para a igualdade formal de direitos.

Portanto, quando se fala em igualdade, deve-se empregar o termo determinando de modo preciso as ideias que a ele se quer associar. Mais ainda, deve-se distinguir com precisão, de um lado, o ideal que se quer atingir e, de outro, a situação que de fato existe; de um lado, a igualdade formal que consiste nos direitos dos indivíduos, nas regras segundo as quais eles são tratados, e, de outro, a igualdade material, que consiste no que de fato eles são tanto do ponto de vista de sua situação material quanto de sua condição pessoal.

Pesquisas na área da biologia e da psicologia bem mostram que os indivíduos diferem nas suas configurações genéticas e disposições afetivas. A afirmação de que todos os seres humanos são iguais não pode basear-se na posse da inteligência, da razão, de certas propensões emocionais, de determinada tendência moral ou de qualquer dado dessa espécie. Em suma, não existe base factual para o princípio da igualdade. Donde se poderia concluir que, longe de remeter a uma assertiva factual, a ideia de igualdade se apresenta como um princípio ético básico ${ }^{35}$.

Com essa afirmação, Nietzsche sem dúvida concordaria. A ideia de que a igualdade não é uma assertiva factual contaria com a sua adesão; aliás, não são poucas as passagens em que ele argumenta nesse sentido. Também a ideia de que a igualdade é um princípio ético básico contaria com o seu assentimento; neste caso, ele se empenharia em mostrar que esse princípio se encontra na base de uma determinada moral: a cristã. Tanto é que, em Para além de bem e mal, ele não hesita em afirmar que "o movimento democrático constitui a herança do movimento cristão"36.

Mas é sobretudo enquanto ideal que jamais se realiza que a ideia de igualdade poderia atrair a atenção de Nietzsche. No Ecce homo, ele declara que “derrubar ídolos (minha palavra para 'ideais') - isso sim, já faz parte

\footnotetext{
${ }^{35}$ Nessa direção, cf. por exemplo P. Singer, Ética prática, Martins Fontes, 1994.

36 KSA 5.125, Para além de bem e mal, §202.
} 
de meu ofício"37. Para tanto, é de extrema relevância o recurso à história. $\mathrm{O}$ trabalho do historiador contribuiria para denunciar as normas de conduta que se apresentam como absolutamente necessárias, apontando o momento de sua produção; concorreria para atacar os juízos que se pretendem universalmente válidos, mostrando as circunstâncias de seu aparecimento; colaboraria, enfim, para desmascarar as generalizações indevidas, ressaltando a especificidade de cada caso. E seria sobretudo imprescindível na crítica dos ideais, na medida em que constituiria uma eficiente arma de combate contra todo e qualquer impulso metafísico.

Da perspectiva nietzschiana, pensar num ideal democrático apresentaria, pelo menos, dois inconvenientes. Antes de mais nada, implicaria comprometer-se com a fabulação metafísica, expediente de que lançam mão os que não se mostram capazes de aceitar esta nossa humana condição e, por isso mesmo, recusam este mundo em que nos achamos aqui e agora em nome de outro, que seria essencial, imutável e eterno. Além disso, acarretaria endossar a ideia de igualdade formal dos membros da sociedade, ideia essa que pressuporia proceder ao nivelamento gregário e à uniformização.

Ora, numa sociedade como a nossa, que se organiza justamente em torno da competição, e esta é tanto maior quanto mais indeterminado for o campo de ação das comparações, cada um tem o direito de julgar que vale tanto quanto qualquer outro, mas não tem como possuir o mesmo valor. Numa sociedade como a nossa, em que o nivelamento promovido pelo consumo apenas aprofunda a desigualdade, a pretensa igualdade social coexiste com consideráveis diferenças de fato, quanto ao poder, à riqueza, à cultura. Numa sociedade como a nossa, em que a igualdade formal de direitos se converte em uniformização consumidora, o ressentimento atinge o seu clímax.

Dentre as descobertas filosóficas mais importantes dos últimos cento e cinqüenta anos, figura, sem sombra de dúvida, a do fenômeno do ressentimento. Ao investigar como os valores morais foram instituídos, Nietzsche diagnosticou com lucidez, por vez primeira, a maneira de pensar, agir e sentir dos ressentidos. Incapaz de reagir, o indivíduo torna-se rancoroso e busca vingar-se. Não logrando equiparar-se ao seu ofensor, sente-se

${ }^{37} \mathrm{KSA} 6.258$, Ecce homo, Prólogo, §2. 
impotente e, então, ressente-se. Mas a inveja, o ciúme e a raiva também são fontes de ressentimento. Ao sentir-se desgostoso por não possuir o que o outro possui, o indivíduo esforça-se por obter o que deseja. Não sendo bem sucedido em seus esforços, sente-se impotente e, então, ressente-se. É sempre de uma certa disposição a comparar-se com o outro que nasce o ressentimento.

Aplicando tais ideias às relações sociais, seria possível sustentar que, quanto maior a distância entre a condição jurídica dos diversos grupos sociais, condição essa dada pelo sistema político ou pela tradição, e o seu poder real, maior será o ressentimento ${ }^{38}$. Num sistema social nitidamente diferenciado ou numa sociedade de castas como por exemplo na Índia, pequeno seria o ressentimento. $\mathrm{E}$, de igual modo, numa democracia que, tanto social quanto politicamente, tendesse à igualdade de riquezas. Levando às últimas consequências esse raciocínio, não há como furtar-se a concluir que, ao fomentar a diferença de status, nossa sociedade promove e provê a cada instante - o ressentimento.

Para tratar de tais questões, é certo que o pensamento nietzschiano pode ser de grande valia. Ele revela seu caráter inovador, quando se trata da crítica à cultura. Nesse contexto, é enquanto imposição do que é uniforme, do que é gregário, que Nietzsche vê a igualdade; por conseguinte, é enquanto supressão das diferenças e singularidades que a concebe. Mas, ao fazer da política objeto da crítica dos valores, é levado a sublinhar que os efeitos nocivos do movimento democrático não se restringiriam à esfera política stricto sensu; eles se dariam a ver na cultura de modo geral. Nessa direção, o filósofo pergunta numa passagem de Para além de bem e mal: "Nós, que somos de outra crença, nós, para quem o movimento democrático não é meramente uma forma de degradação da organização política, mas uma forma de degradação, ou seja, de apequenamento do homem, sua mediocrização e rebaixamento de valor: para onde temos nós de apontar nossas esperanças?" ${ }^{39}$. É dessa forma pouco usual nos dias hoje que ele se posiciona em relação à democracia; é dessa maneira polêmica que dela trata.

\footnotetext{
${ }^{38}$ É o que faz Max Scheler. Cf. L'homme du ressentiment. Paris: Gallimard, 1970.

39 KSA 5.126, Para além de bem e mal, §203.
} 
O exame de diversas passagens em que Nietzsche se ocupa com a tendência democrática da modernidade me leva a julgar ambivalente a posição que adota. Se no âmbito da crítica da cultura ele se mostra inovador, é certo que, em seus ataques à tendência democrática dos tempos modernos, toma a defesa do aristocratismo. A meu ver, importa ressaltar aqui que, embora julgue que não se pode ignorar as consequências no domínio cultural da ideia de igualdade entendida enquanto nivelamento gregário e uniformização, antecipando assim a crítica que veio a ser posteriormente desenvolvida do que se chamou de indústria cultural, Nietzsche assume posições com consequências políticas dificilmente defensáveis nos dias de hoje. 


\section{Referências:}

ACAMPORA. C. D, "Demos Agonists Redux. Reflections of the Streit of Political Antagonism", in: Nietzsche-Studien 32 (2003), p. 374-390.

ANSELL-PEARSON, K. An Introduction to Nietzsche as Political Thinker. Cambridge: University Press, 1994.

A Study of Nietzsche's Moral and Political Thought. Cambridge:

University Press, 1992.

APPEL, A. Nietzsche contra Democracy. Ithaca: Cornell University Press, 1999.

BERGMANN, P. Nietzsche. The "Last Anti-Political German". Bloomington: Indiana University Press, 1987.

BROBJER, T.H. "The Absence of Political Ideals in Nietzsche's Writings", in: Nietzsche-Studien 27 (1998), p. 300-318.

. "Nietzsche as Political Thinker. A Response to D. DOMBOWSKY", in:

Nietzsche-Studien 30 (2001), p. 394-396.

CAMPIONI, G. Lectures françaises de Nietzsche. Trad. Christel LavigneMouilleron. Paris: PUF, 2001.

CONNOLY, W. Political Theory and Modernity. Oxford: University Press, 1989.

CONWAY, D. W. Nietzsche and the Political. Londres: Routledge, 1997.

DETWILER, B. Nietzsche and the Politics of Aristocratic Radicalism. Chicago: University of Chicago Press, 1990.

DOMBOWSKY, D. "A Response to Thomas H. Brobjer's 'The Absence of Political Ideals in Nietzsche's Writings”, in: Nietzsche-Studien 30 (2001), p.387-393.

. “A Response to Alan D. Schrift's 'Nietzsche for Democracy?", in:

Nietzsche-Studien 31 (2002), p. 278-290.

GOYARD-FABRE, S. Nietzsche et la question politique. Paris: Sirey, 1977.

HATAB, L. J. A Nietzschean Defense of Democracy. An Experiment in Postmodern Politics. Chicago: Open Court, 1995.

HONIG, B. Political Theory and the Displacement of Politics. Ithaca: Cornell University Press, 1993.

MARTI, U. "Der grosse Pöbel- und Sklavenaufstand". Nietzsches Auseinandersetzung mit Revolution und Demokratie. Stuttgart: Metzler, 1993.

MARTON, S. "Nietzsche e a Revolução Francesa", in Extravagâncias. Ensaios sobre a filosofia de Nietzsche. São Paulo: Barcarolla, $3^{\text {a }}$ ed., 2009. 
NIETZSCHE, F. Sämtliche Werke - Kritische Studienausgabe, edição organizada por Giorgio Colli e Mazzino Montinari. Berlim: Walter de Gruyter \& Co., 1967/1978. 15 vol.

. Obras Incompletas da coleção "Os Pensadores”. São Paulo: Abril Cultural, $2^{\mathrm{a}}$ edição, 1978.

OWEN., D. Nietzsche, Politics and Modernity. A Critical of Liberal Reason. Londres: Thousand Oaks, 1995.

MCINTYRE, A. The Sovereignty of Joy. Nietzsche's Vision of Grand Politics. Toronto: University of Toronto Press, 1997.

. "Virtuosos of Contempt': An Investigation of Nietzsche's Political Philosophy Through Certain Platonic Political Ideas", in: Nietzsche-Studien 21 (1992), p.184-210.

OTTMANN, H. Philosophie und Politik bei Nietzsche. Berlin: de Gruyter, 1987.

SCHELER, M. L'homme du ressentiment. Paris: Gallimard, 1970.

SCHRIFT, A. "Nietzsche for Democracy?", in: Nietzsche-Studien 29 (2000), p. 220232.

291-297.

. "Response to Don Dombowsky", in: Nietzsche-Studien 31 (2002), p.

SEDGWICK, P. "Violence, Economy and Temporality. Plotting the Political Terrain of On the Genealogy of Morality", in: Nietzsche-Studien 34 (2005), p.163-185.

SINGER, P. Ética prática. São Paulo: Martins Fontes, 1994.

SIEMENS, H. "Nietzsche's Political Philosophy : A Review of Recent Literature", in: Nietzsche-Studien 30 (2001), p.508-526.

WARREN, M. Nietzsche and Political Thought. Cambridge: Mass, 1988.

Email: smarton@usp.br

Recebido: Abril/2011

Aprovado: Maio/2011 